\title{
Efeito do sistema de cultivo na produção de gladíolos no Alto Vale do Itajaí, SC
}

\author{
Alexandra Goede de Souza', Fernanda Gonçalves Broggiatto², David Pires de Azeredo Neto², \\ Leosane Cristina Bosco ${ }^{3}$ e Eduardo Affonso Jung ${ }^{2}$
}

\begin{abstract}
Resumo - O objetivo deste trabalho foi avaliar o efeito do sistema de cultivo no desenvolvimento das plantas e na qualidade das hastes florais de gladíolos. O delineamento experimental utilizado foi inteiramente casualizado com dois cultivares: White Goddess e Red Beauty; duas datas de colheita: Dias das Mães (DM) e Dia dos namorados (DN); e dois sistemas de cultivo: convencional e mínimo. Nas plantas foram avaliados: número de folhas, massa seca total, número de floretes, dias para emergência, ponto de colheita, comprimento e diâmetro da haste. Para Red Beauty cultivado para o DM, o cultivo mínimo proporcionou maior número de folhas, comprimento e diâmetro da haste; e para o DN, aumento da massa seca, do número de floretes e dias para emergência. Para White Goddess houve efeito do sistema de cultivo somente no DM, quando as plantas apresentaram, no cultivo mínimo, maior diâmetro e comprimento da haste e menor da massa seca. Para Red Beauty, $83,4 \%$ e $25 \%$ das hastes foram classificadas como extra no cultivo mínimo e convencional, respectivamente, enquanto o White Goddess apresentou $100 \%$ das hastes como extra em ambos os sistemas de cultivo.
\end{abstract}

Termos para indexação: Gladiolus x grandiflorus Hort.; Cultivo mínimo; Qualidade da haste.

\section{Effect of cultivation system on gladiolus production in Alto Vale do Itajaí, SC}

Abstract - The aim of this work was to evaluate the effect of the cultivation system on plant development and the quality of floral stems of gladiolus. The experimental design was completely randomized with two cultivars: White Goddess and Red Beauty; two harvest dates: Mother's Day (MD) and Valentine's Day (VD); and two cultivation systems: conventional and minimum. In the plants were evaluated the number of leaves, total dry mass, number of flowers in the stem, days for the emergence and harvested, stem length and diameter. For cultivar Red Beauty cultivated for MD, the minimum cultivation provided a greater number of leaves, high stem length and diameter; while for VD, the minimum cultivation provided more dry mass, number of flowers in stem and days for emergence. For White Goddess was detected effect of the cultivation system only on MD cultivation. The plants presented high stem length and diameter in the minimum cultivation system, but presented lower dry mass. For Red Beauty, $83.4 \%$ and $25 \%$ of the stems were classified as extra in minimum and conventional cultivation, respectively, while White Goddess presented $100 \%$ of the stems as extra in both cultivation systems.

Index terms: Gladiolus x grandiflorus Hort.; Minimum cultivation; Stem quality.

\section{Introdução}

Nos últimos anos, a floricultura brasileira vem apresentando crescimento anual de $8 \%$ a $10 \%$ no volume de produção de plantas ornamentais (JUNQUEIRA \& PEETZ, 2014). O estado de São Paulo ocupa $45 \%$ da área total cultivada no país, com aproximadamente 7 mil hectares, sendo caracterizado como maior produtor nacional de plantas ornamentais (IBRAFLOR, 2015). Embo- ra a cadeia produtiva de flores e plantas ornamentais do Brasil tenha como destino principal o mercado interno, o país ainda necessita importar produtos para atender a sua demanda. Em 2014, o segmento flores de corte foi responsável por $58 \%$ das importações brasileiras de plantas ornamentais (IBRAFLOR, 2015).

Santa Catarina ocupa a terceira posição no ranking de área plantada, com cerca de mil hectares, em aproximada- mente 115 municípios, envolvendo 750 famílias, com faturamento estimado de R\$ 61,2 milhões (IBRAFLOR, 2015). No Estado predominam pequenos produtores, que praticam agricultura familiar. Da produção total, $93 \%$ é realizada diretamente no solo e em ambiente descoberto, principalmente devido à menor necessidade de investimento, razão pela qual Santa Catarina se caracteriza como um estado de baixo investimento tecnológico no setor. Mesmo assim, or

Recebido em 28/1/2020. Aceito para publicação em 22/6/2020.

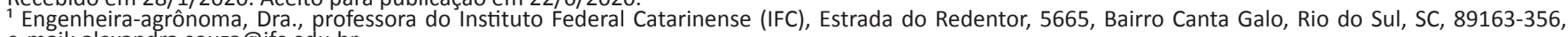
e-mail: alexandra.souza@ifc.edu.br

${ }^{2}$ Graduando em Engenharia-agronômica, IFC, e-mail: fer nandapso@hotmail.com; davidpiresazeredo@gmail.com; eduardojung2000@outlook.com

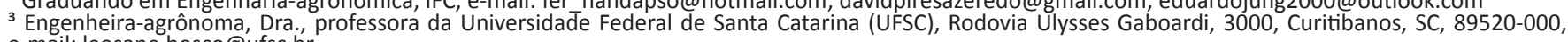
e-mail: leosane.bosco@ufsc.br 
Estado é autossuficiente na produção de plantas ornamentais destinadas ao paisagismo, importando somente flores de corte e de vaso de outros estados (IBRAFLOR, 2015).

Dentre as plantas ornamentais comercializadas estão as flores de corte, sendo o gladíolo (Gladiolus x grandiflorus Hort.) um importante representante deste grupo (SCHWAB et al., 2019). A produção brasileira desta planta está concentrada especialmente no estado de São Paulo, nos municípios de Holambra e Santo Antônio de Posse, seguido pelos estados do Rio de Janeiro, Pernambuco, Bahia e Rio Grande do Sul (TOMBOLATO et al., 2010). Informações sobre área plantada e a produção são escassas. No entanto, no Rio Grande do Sul e em Santa Catarina a produção da flor vem aumentando, principalmente por pequenos produtores rurais, que as comercializam diretamente aos consumidores, encurtando a cadeia (SCHWAB et al., 2019).

Tradicionalmente o cultivo do gladíolo ocorre para o dia de finados, porém, trabalhos recentes realizados na Região Sul do Brasil indicam que é possível a produção de hastes florais para serem comercializadas em outras importantes datas comemorativas, como o DM, o DN e as festas de fim de ano (SCHWAB et al., 2015), exigindo planejamento da produção por parte dos produtores. Atualmente, o agendamento da produlizando o modelo PhenoGlad, que está disponível na forma de aplicativo para os estados do RS e SC (UHLMANN et al., 2017). Outro aspecto importante é o incentivo ao emprego do gladíolo como fonte de diversificação e renda para as pequenas propriedades rurais familiares, contribuindo na redução do êxodo rural (UHLMANN et al., 2019).

As plantas de gladíolo podem se desenvolver adequadamente em algumas condições edafoclimáticas adversas (SCHWAB et al., 2015; ROSA et al., 2014). No entanto, podem apresentar respostas diferenciadas de desenvolvimento, em especial à temperatura (SCHWAB et al., 2015) e à disponibilidade hídrica (PEREIRA et al., 2009) durante o cultivo, condições as quais podem causar danos às plantas e afetar a ção de gladíolo pode ser realizado uti- qualidade final da haste floral. Uhlmann et al. (2017) relatam que menores temperaturas do ar e do solo aumentam o ciclo da cultura, incluindo o tempo para emergência.

O manejo adequado do solo é fundamental para o desenvolvimento das plantas e das hastes florais de gladíolos. No Brasil, predomina o sistema convencional de cultivo, com revolvimento intensivo do solo, para a grande maioria das culturas agrícolas, incluindo o gladíolo (SCHWAB et al., 2019).

No entanto, trabalhos mostram o efeito positivo do cultivo mínimo no desenvolvimento das plantas de diferentes espécies (SILVA et al., 2015; COELHO et al., 2013). O melhor desenvolvimento é atribuído à manutenção da umidade no solo, ciclagem de nutrientes, redução da amplitude térmica no solo, menor densidade populacional de plantas daninhas, além da redução da perda de nutrientes e de solo por erosão (COELHO et al., 2013; BERTOL et al., 2007).

Em cebola foi reportado que o cultivo mínimo possibilitou maiores teores de carbono e nitrogênio total no solo em relação ao plantio convencional. Teores superiores no cultivo mínimo deve-se à contribuição das plantas de cobertura deixadas na superfície do solo, comparativamente ao convencional (SILVA et al., 2014).

Diante do exposto, o objetivo do trabalho foi avaliar o efeito do sistema de cultivo convencional e cultivo mínimo no desenvolvimento de plantas e qualidade das hastes florais de gladíolos produzidos para as datas comemorativas

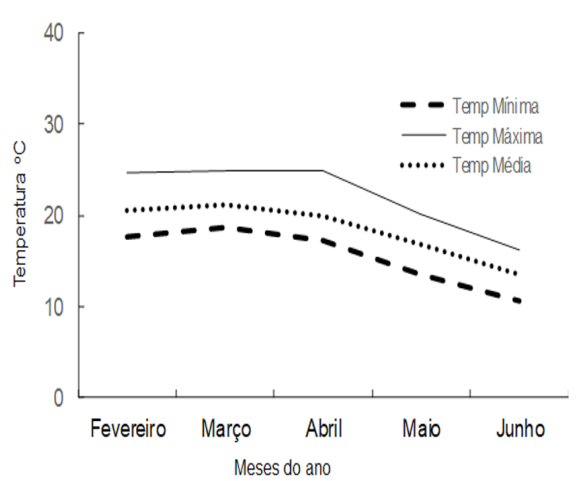

Figura 1. Temperatura mínima, média e máxima e precipitação nos meses de condução do experimento

Figure 1. Minimum, average and maximum temperature and precipitation in the months of the experiment

do Dia das Mães (DM) e Dia dos Namorados (DN), nas condições do Alto Vale do Itajaí, SC.

\section{Material e métodos}

O experimento foi realizado em Rio do Sul, SC, no ano de 2018, com plantios de gladíolos dos cultivares White Goddess e Red Beauty com colheita simulada para o DM e o DN. O planejamento da data de plantio e as práticas de manejo seguiram a indicação do aplicativo PhenoGlad Mobile SC ${ }^{1}$ (SCHWAB et al., 2019; UHLMANN et al., 2017), com data de plantio I: no dia 19 de fevereiro de 2018 (para colheita simulada para o DM); e data de plantio II: no dia 09 de março de 2018 (para colheita simulada para o DN). Os dados de temperatura e precipitação de fevereiro a junho foram coletados em estação meteorológica instalada no IFC (Figura 1).

Cormos ou bulbos de gladíolos foram plantados em solo conduzido em dois sistemas de cultivo: convencional e mínimo. No sistema convencional os canteiros foram preparados com auxílio de um encanteirador nas dimensões de $10 \mathrm{~m}$ de comprimento e $1 \mathrm{~m}$ de largura para cada cultivar.

O plantio no cultivo mínimo foi realizado sobre palhada de crotalária (Crotalaria juncea) e milheto (Pennisetum glaucum) (semeado no mês de novembro de 2017), previamente dessecada. Em ambos os sistemas, foram abertas linhas com $15 \mathrm{~cm}$ de profundidade. Ao total foram cultivados oito canteiros, quatro para cada data de plantio.

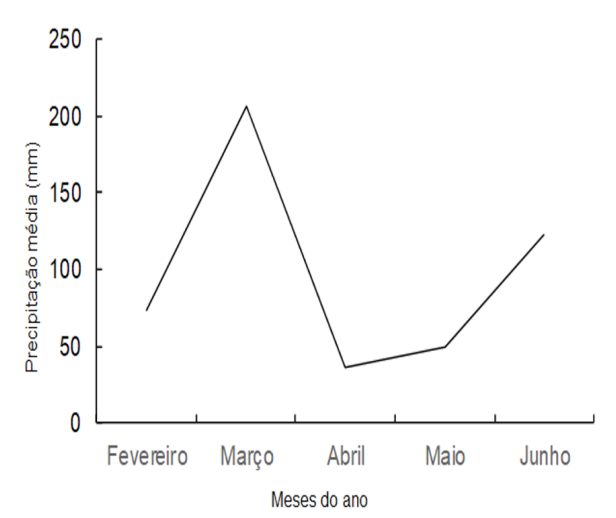


$\mathrm{O} \mathrm{pH}$ do solo foi corrigido para 6,0 (SCHWAB et al., 2019) de acordo com a análise do solo: $\mathrm{pH}$ em água de 5,50; $8,70 \mathrm{mg} \mathrm{dm}{ }^{3}$ de $P ; 158,00 \mathrm{mg} \mathrm{dm} \mathrm{dm}^{3}$ de

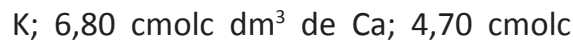

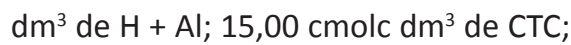

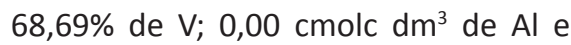
$4,30 \%$ de M.O. Foi realizada adubação de base nas linhas com 20g de NPK (414-8) por metro linear e os cormos plantados em espaçamento de $40 \mathrm{~cm}$ entre linhas e $20 \mathrm{~cm}$ entre plantas, conforme indicado no aplicativo PhenoGlad mobile SC (SCHWAB et al., 2019). Cada tratamento recebeu 100 cormos. Os cormos utilizados no experimento foram obtidos do Veiling Holambra. No estádio de desenvolvimento $\mathrm{V} 3$ (quando as plantas apresentam 3 folhas) (SCHWAB et al., 2015) foi realizada adubação de cobertura com $14 \mathrm{~g}$ de Ureia ( $45 \%$ de N) e $14 \mathrm{~g}$ de cloreto de potássio ( $60 \%$ de $\mathrm{K}$ ) por metro linear. Para evitar o tombamento e manter o crescimento ereto das hastes, as plantas foram tutoradas com fitilhos nos estádios de sete folhas (V7) e no início do espigamento (R1.0) (SCHWAB et al., 2015).

Em cada tratamento foram marcadas 12 plantas, nas quais foram avaliadas características de crescimento (número de folhas, massa seca e número de floretes), desenvolvimento (identificação de estádios de emergência, vegetativos e reprodutivos) e qualidade de hastes florais (comprimento e diâmetro da haste).

O número de folhas foi contabilizado, semanalmente, desde a emergência das plantas (EM) até o início do espigamento (R1.0). Para determinação da massa seca foram colhidas seis plantas (não marcadas) de cada tratamento no estádio V6 (planta com seis folhas) e R2 (ponto de colheita 1). As plantas foram colhidas, os cormos lavados para remoção do solo, e as plantas inteiras acondicionadas em sacos de papel pardo para secagem em estufa de circulação de ar forçada a $65^{\circ} \mathrm{C}$ até peso constante e os resultados expressos em gramas de massa seca (MS) por planta. O número de floretes por haste floral foi contabilizado em cada planta marcada no momento da abertura do último florete da haste.

A data de emergência foi estabele- cida quando $50 \%$ das plantas apresentavam brotações visíveis acima do nível do solo, determinando-se a duração da fase de emergência (plantio-emergência/PL-EM). A data de ocorrência de R2 foi considerada quando $50 \%$ das plantas mostravam a coloração dos primeiros três botões florais da haste (SCHWAB et al., 2015). A partir disso, determinou-se a duração da fase EM-R2.

Quando as hastes florais estavam no estádio R2 foram avaliados o comprimento e o diâmetro total. O comprimento da haste floral foi determinado pela medida direta no nível do solo até a ponta da espiga e classificada como: média - haste com comprimento de $75 \mathrm{~cm}$; longa - haste com comprimento de $90 \mathrm{~cm}$; e extra - haste com comprimento de $110 \mathrm{~cm}$. Hastes com comprimento menor que $75 \mathrm{~cm}$ não são classificadas no padrão Veiling Holambra (TOMBOLATO et al., 2010). A avaliação do diâmetro da haste floral foi realizada com auxílio de um paquímetro digital, logo abaixo da inserção do primeiro florete e classificados de acordo com a classe de comprimento: média - espessura mínima de $0,5 \mathrm{~cm}$; longa - espessura mínima de $0,8 \mathrm{~cm}$; e extra - espessura mínima de 1,0cm (TOMBOLATO et al., 2010).

O delineamento experimental utilizado foi inteiramente casualizado em parcelas subdivididas com dois cultivares e dois sistemas de cultivo em duas datas de plantio. Cada época de plantio, cultivar e sistema de cultivo foi representado por um canteiro com 100 plantas. Os dados foram submetidos à análise da variância (Anova) e as médias dos tratamentos comparadas pelo teste de Tukey $5 \%$ de probabilidade utilizando o programa SASM-Agri (CANTERI et al., 2001).

\section{Resultados e discussão}

A análise dos dados indicou que houve efeito do sistema de cultivo sobre alguns dos atributos avaliados para o cultivar White Goddess cultivado para colheita no DM e para o cultivar Red Beauty em ambas as datas de colheita.

$\mathrm{O}$ número de folhas não foi influenciado pelo sistema de cultivo, exceto para o cultivar Red Beauty cultivado para o $\mathrm{DM}$, com valores médios de $6,8 \mathrm{e}$ 8,6 folhas para o cultivo convencional e mínimo, respectivamente (Tabela 1). 0 número de folhas é uma característica genética dos cultivares, mas ele pode sofrer influência das condições de cultivo. Para o cultivar de gladíolo San Remo, produzido em Dourados, MS, o número de folhas por planta foi menor quando da aplicação de adubação nitrogenada em doses superiores a $30 \mathrm{~kg} \mathrm{ha}^{-1}$, variando de 9,9 a 17,4 folhas/planta (ROSA et al., 2014).

A massa seca total média apresentou efeito do sistema de cultivo para White Goddess para colheita no DM com $35,7 \mathrm{~g}$ planta ${ }^{-1}$ no cultivo convencional e 24g planta $^{-1}$ no cultivo mínimo (Tabela 1). Para Red Beauty, a massa seca total média foi superior no sistema de cultivo mínimo (29,8g planta $\left.{ }^{-1}\right)$ quando comparado ao convencional $\left(17,6\right.$ planta $\left.^{-1}\right)$ para colheita simulada no DN. Nos demais tratamentos não houve efeito dos sistemas de cultivo. $O$ efeito do cultivo mínimo pode estar relacionado com a menor densidade e a maior porosidade dos solos manejados neste sistema, disponibilizando mais água e garantindo melhor desenvolvimento das culturas (SILVA et al., 2015). Neste estudo não foram realizadas análises físicas do solo, sendo sugestão para trabalhos futuros avaliar o efeito do sistema de cultivo nestas características para esta cultura.

O número de floretes por haste variou de 14,7 a 15,7 com White Goddess, não apresentando diferença significativa entre os sistemas de cultivo. No entanto, o cultivar Red Beauty, no sistema de cultivo mínimo do DN, formou maior número de floretes que em sistema convencional.

A emergência foi afetada pelo sistema de cultivo somente para Red Beauty, que necessitou de dois dias a mais para a emergência dos cormos em cultivo mínimo (14,3 dias) quando comparado ao cultivo convencional (12,3 dias) para coIheita no DN (Tabela 1). Para colheita no DM, em ambos os cultivares não houve efeito do sistema de cultivo, assim como para White Goddess na colheita para o DN (Tabela 1). Em gladíolos produzidos na região central do RS, o tempo de emergência variou de 6 a 39 dias de acordo com o cultivar e a época de 
Tabela 1. Atributos de crescimento e qualidade das hastes florais de gladíolos nos cultivares White Goddess e Red Beauty cultivados em dois sistemas de cultivo e duas épocas de colheita

Table 1. Growth and quality flower stems attributes of gladiolus in White Goddess and Red Beauty cultivars grown in two cropping systems and two harvest seasons

\begin{tabular}{|c|c|c|c|c|}
\hline & \multicolumn{4}{|c|}{ Cultivar White Goddess } \\
\hline & \multicolumn{2}{|c|}{ Dia das Mães } & \multicolumn{2}{|c|}{ Dia dos Namorados } \\
\hline & $\begin{array}{c}\text { Cultivo } \\
\text { Convencional }\end{array}$ & $\begin{array}{l}\text { Cultivo } \\
\text { mínimo }\end{array}$ & $\begin{array}{c}\text { Cultivo } \\
\text { Convencional }\end{array}$ & $\begin{array}{l}\text { Cultivo } \\
\text { mínimo }\end{array}$ \\
\hline Número de folhas & 8,9 a & $9,5 \mathrm{a}$ & $7,2 \mathrm{a}$ & 7,8 a \\
\hline Massa seca total (g/planta) & $35,7 a$ & $24 \mathrm{~b}$ & 30,6 a & 28,6 a \\
\hline Número de floretes & 15,6 a & $14,7 \mathrm{a}$ & $15,7 \mathrm{a}$ & 15,5 a \\
\hline Emergência (dias) & 16,3 a & 15,3 a & 13,3 a & 14,3 a \\
\hline EM-R2 (dias) & $69,1 \mathrm{a}$ & 75,7 a & $103,2 \mathrm{a}$ & $102,5 \mathrm{a}$ \\
\hline Diâmetro da haste $(\mathrm{cm})$ & $0,5 \mathrm{~b}$ & $0,7 \mathrm{a}$ & 0,7 a & 0,7 a \\
\hline \multirow[t]{2}{*}{ Comprimento da haste $(\mathrm{cm})$} & $114 \mathrm{~b}$ & 133 a & $130 \mathrm{a}$ & $131 \mathrm{a}$ \\
\hline & \multicolumn{4}{|c|}{ Cultivar Red Beauty } \\
\hline Número de folhas & $6,8 \mathrm{~b}$ & 8,6 a & $7,4 \mathrm{a}$ & 7,0 a \\
\hline Massa seca total (g/planta) & $15,1 \mathrm{a}$ & 16,7 a & $17,6 \mathrm{~b}$ & 29,8 a \\
\hline Número de floretes & 10,7 a & 12,3 a & $12,3 b$ & $15,1 \mathrm{a}$ \\
\hline Emergência (dias) & 14,3 a & 13,3 a & $12,3 \mathrm{~b}$ & 14,3 a \\
\hline EM-R2 (dias) & $78,1 \mathrm{a}$ & $73,2 \mathrm{a}$ & 99,9 a & 103,3 a \\
\hline Diâmetro da haste $(\mathrm{cm})$ & $0,5 \mathrm{~b}$ & $0,7 \mathrm{a}$ & $0,5 \mathrm{a}$ & $0,6 \mathrm{a}$ \\
\hline $\begin{array}{l}\text { Comprimento da haste }(\mathrm{cm}) \\
\text { Médias seguidas peta mesma tetra, }\end{array}$ & $\begin{array}{l}86 \mathrm{~b} \\
\text { timhta, entre }\end{array}$ & $\begin{array}{l}106 \text { a } \\
\text { is decultiv }\end{array}$ & $\begin{array}{l}113 \text { a } \\
\text { não diferem }\end{array}$ & $\begin{array}{l}108 \text { a } \\
\text { ativament }\end{array}$ \\
\hline
\end{tabular}

entre si, pelo teste de Tukey a $5 \%$ de probabilidade.

plantio. O menor tempo para emergência está associado ao plantio em períodos mais quentes, reduzindo o ciclo de desenvolvimento da cultura; e o maior tempo, ao plantio nos períodos mais frios, que estendem o ciclo (SCHWAB et al., 2018). Como neste trabalho os plantios foram realizados em períodos fora dos extremos de temperatura, a emergência apresentou valores intermediários, próximos aos apresentados por Schwab et al. (2018) com plantios realizados nos mesmos períodos.

Não houve efeito do sistema de cultivo quanto à duração do período Emergencial (EM)-R2, com valores médios para White Goddess no cultivo mínimo de 75,7 e 102,5 dias. No cultivo convencional a duração dessa fase foi de 69,1 e 103,2 dias, respectivamente, para colheita no DM e DN (Tabela 1). Isso ocorre porque a temperatura do ar é o elemento determinante para o desenvolvimento das plantas de gladíolo, pois em temperaturas mais baixas o ciclo de desenvolvimento se alonga (caso do experimento do DN durante início do outono), enquanto os dias com temperaturas mais elevadas encurtam o ciclo (caso do experimento do dia DM) (UHLMANN et al., 2018).

O diâmetro das hastes apresentou diferenças entre os sistemas de cultivo para os dois cultivares no experimento para colheita no DM. Os diâmetros variaram de $0,58 \mathrm{~cm}$ a $0,75 \mathrm{~cm}$ para White Goddess e $0,58 \mathrm{~cm}$ a $0,76 \mathrm{~cm}$ para Red Beauty para plantio em sistema con(Tabela 1). Esses valores são inferiores aos diâmetros obtidos para o cultivar Jester, plantado nos meses de fevereiro $(0,89 \mathrm{~cm})$ e março $(1,03 \mathrm{~cm})$ em sistema convencional em Santa Maria, RS. Estas vencional e mínimo, respectivamente diferenças podem ser atribuídas às diferentes condições edafoclimáticas, bem como ao cultivar (SCHWAB et al., 2015).

$\mathrm{O}$ comprimento da haste foi influenciado pelo sistema de cultivo em ambos os cultivares quando plantados para colheita no DM. Para o DN não houve efeito significativo dos tratamentos analisados. Para White Goddess o comprimento total da haste foi de $133 \mathrm{~cm}$ no cultivo mínimo e de $114 \mathrm{~cm}$ no convencional (Tabela 1). Para Red Beauty o comprimento também foi superior no cultivo mínimo com $106 \mathrm{~cm}$, enquanto no convencional foi de $86 \mathrm{~cm}$ (Tabela 1). O maior comprimento das hastes no cultivo mínimo com plantio para o DM pode estar relacionado à melhor manutenção da temperatura e à umidade do solo, fornecendo melhores condições para o desenvolvimento das plantas. No plantio para o DN, o solo tem maior variabilidade térmica, pois as temperaturas já estão em declínio devido ao início do inverno, reduzindo o efeito do calor e do sistema de cultivo para essa data (SEVERINO, 2007).

Diâmetros e comprimentos maiores podem aumentar a resistência da haste floral, especialmente aos danos mecânicos, como a quebra da haste, que pode ocorrer tanto na lavoura durante o crescimento das plantas quanto na colheita e pós-colheita. Hastes mais longas e de maior diâmetro também apresentam maior reserva de carbono, aumentando a durabilidade pós-colheita das hastes florais (FARIAS et al., 2013). Além disso, hastes longas permitem a realização de cortes na base para renovar os tecidos e restabelecer a absorção de água, aumentando o tempo de vida em pós-coIheita (SCHWAB et al. 2015).

A Tabela 2 apresenta a Anova com o resumo das análises de variância dos atributos avaliados nos dois cultivares em dois sistemas de cultivos e as datas de colheita.

A Figura 2 apresenta a classe de comercialização das hastes de gladíolo em função do comprimento para os dois cultivares nos dois sistemas de cultivo nas datas de plantio para colheita no DM e DN. Para colheita no DM, 83,4\% e $100 \%$ das hastes foram classificadas na classe extra para os cultivares Red Beauty e White Goddess, respectivamente, 
Tabela 2. Resumo das análises de variância dos caracteres diâmetro (D), comprimento do pendão (C), número de floretes (NF), EM-R2, massa seca (MS) emergência (EM) de dois cultivares (White (W) e Red (R)) avaliados em dois sistemas de cultivo em duas datas de colheita Table 2. Summary of analysis of variance of the characters diameter (D), tassel length (C), number of florets (NF), EM-R2, dry mass (MS) emergence (EM) of two cultivars (White (W) and Red (R)) evaluated in two cultivation systems for two harvest dates

\begin{tabular}{|c|c|c|c|c|c|c|c|c|c|c|c|c|c|}
\hline \multirow{2}{*}{$\begin{array}{l}\text { Causas de } \\
\text { variação }\end{array}$} & \multirow{2}{*}{$\mathrm{GL}$} & \multicolumn{12}{|c|}{ QUADRADO MÉDIO ${ }^{1}$} \\
\hline & & $\begin{array}{c}D \\
(W)\end{array}$ & $\begin{array}{c}D \\
(R)\end{array}$ & $\begin{array}{c}C \\
\text { (W) }\end{array}$ & $\begin{array}{c}C \\
(R)\end{array}$ & NF (W) & $\begin{array}{l}N F \\
(R)\end{array}$ & EM-R2 (W) & EM-R3 (R) & $\begin{array}{l}\text { MS } \\
\text { (W) }\end{array}$ & $M S(R)$ & $\begin{array}{l}\text { EM } \\
\text { (W) }\end{array}$ & $\mathrm{EM}(\mathrm{R})$ \\
\hline Tratamentos & 3 & $0,098 * *$ & $0,125^{* *}$ & $0,098^{* *}$ & $0,176 * *$ & $0,566^{\text {ns }}$ & $40,5 * *$ & $3801,8 * *$ & $2758,3 * *$ & $139,53^{\text {ns }}$ & $273,3^{*}$ & $4,065^{* *}$ & $2,7 * *$ \\
\hline Resíduo & 44 & 0,014 & 0,012 & 0,006 & 0,019 & 4,412 & 5,8 & 296,4 & 16,0 & 52,31 & 37,8 & 0,333 & 0,333 \\
\hline
\end{tabular}

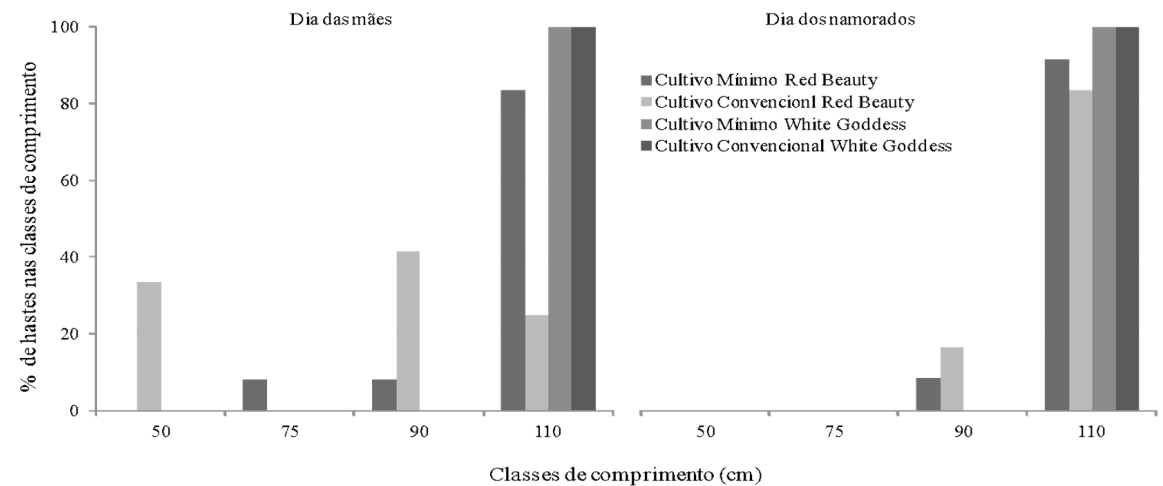

Figura 2. Classes de comprimento das hastes florais de gladíolo White Goddess e Red Beauty cultivados em dois sistemas de cultivo para duas épocas de colheita Figure 2. Length classes of gladiolus flower stems of White Goddess and Red Beauty cultivated in two cropping systems for two harvest seasons

no sistema de cultivo mínimo. No cultivo convencional, o cultivar Red Beauty apresentou somente $25 \%$ das hastes na classe extra, $41,6 \%$ na classe longa e $33,4 \%$ ficaram abaixo da classe média. Enquanto a White Goddess apresentou $100 \%$ das hastes na classe extra.

Os gladíolos dos cultivares Red Beauty e White Goddess plantados para colheita no DN apresentaram 91,6\% e $100 \%$ e 83,4 e $100 \%$ das hastes classificadas na classe extra, respectivamente, nos sistemas de cultivo mínimo e convencional (Figura 2). Schwab et al. (2015), trabalhando com diferentes cultivares de gladíolo em sistema de plantio convencional e diferentes datas de plantio no RS, obtiveram valores médios de $31,3 \%$ das hastes classificadas na classe extra, $54,7 \%$ na classe longa e $14,1 \%$ na classe média, valores inferiores às médias obtidas nas condições deste trabalho.

A produção de gladíolos em sistema de cultivo mínimo teve maior efeito no comprimento das hastes para o cultivar Red Beauty quando plantadas para coIheita no DM, uma vez que apresentou mais hastes classificadas nas classes longa e extra do que no sistema de cultivo convencional.

O cultivar Red Beauty apresentou $91,6 \%$ das hastes classificadas com di- âmetro abaixo de $0,5 \mathrm{~cm}$ e $8,4 \%$ com diâmetro de $0,8 \mathrm{~cm}$ no cultivo convencional para colheita no DM (Figura 3). Porém, quando cultivado em sistema de cultivo mínimo, somente $16,6 \%$ das hastes apresentaram diâmetro inferior a $0,5 \mathrm{~cm}$. As demais hastes foram classificadas com diâmetro de $0,5 \mathrm{~cm}(25 \%)$, $0,8 \mathrm{~cm}(50 \%)$ e $1,0 \mathrm{~cm}(8,4 \%)$ (Figura 3), indicando o efeito positivo do cultivo mínimo do solo no diâmetro das hastes florais de gladíolo. Para colheita no DN o Red Beauty apresentou $8,4 \%$ das hastes classificadas em $0,5 \mathrm{~cm}, 75 \%$ em $0,8 \mathrm{~cm}$ e $16,6 \%$ em $1,0 \mathrm{~cm}$ de diâmetro em cultivo mínimo. Em cultivo convencional $75 \%$ das hastes foram classificadas na classe de diâmetro de $0,8 \mathrm{~cm}$ e $25 \%$ na classe $1,0 \mathrm{~cm}$ (Figura 3).

O cultivar White Goddess, no sistema de cultivo mínimo com colheita para o DM, apresentou $91,6 \%$ das hastes classificadas na classe de diâmetro $0,8 \mathrm{~cm}$ e $8,4 \%$ na classe de $1,0 \mathrm{~cm}$, enquanto no sistema de cultivo convencio- -

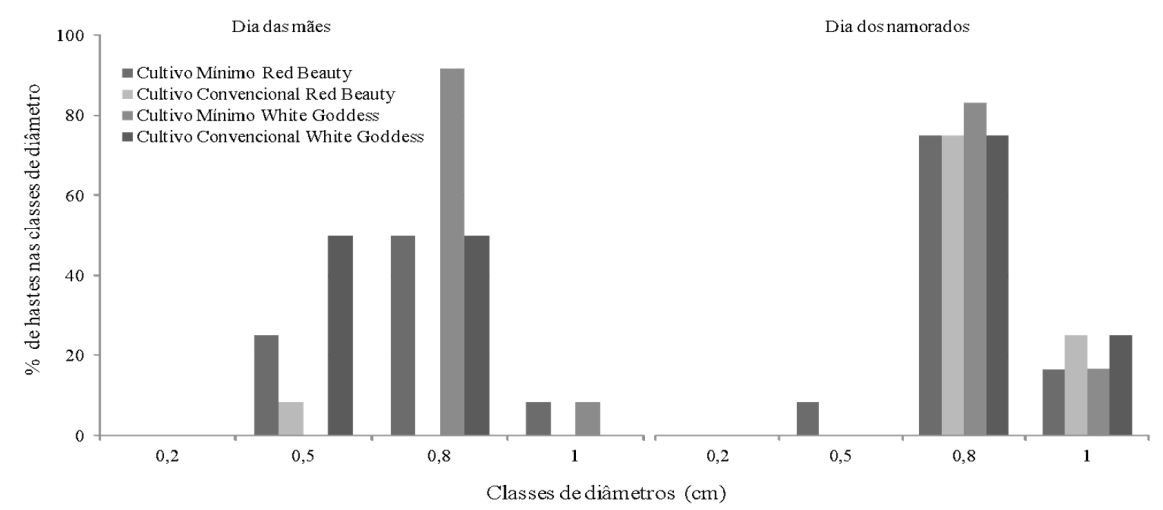

Figura 3. Classes de diâmetro das hastes florais de gladíolo White Goddess e Red Beauty cultivados em dois sistemas de cultivo para duas épocas de colheita

Figure 3. Diameter classes of gladiolus flower stems of White Goddess and Red Beauty cultivated in two cropping systems for two harvest seasons 
nal $50 \%$ das hastes foram classificadas na classe de diâmetro $0,5 \mathrm{~m}$ e $50 \%$ na classe $0,8 \mathrm{~cm}$ (Figura 3). Para o DN, 75\% das hastes apresentaram classificação na classe $0,8 \mathrm{~cm}$ e $25 \%$ na classe $1,0 \mathrm{~cm}$ no sistema convencional e $83,3 \%$ na classe $0,8 \mathrm{~cm}$ e $16,7 \%$ na classe $1,0 \mathrm{~cm}$ no sistema de cultivo mínimo (Figura 3).

Os dados indicam maior efeito do cultivo mínimo para o atributo de diâmetro em ambos os cultivares quando plantio realizado com colheita planejada para o DM. Tal efeito pode ser atribuído às maiores temperaturas neste período, evidenciando que a manutenção da palhada sobre a superfície do solo promove melhor desenvolvimento do diâmetro das hastes.

\section{Conclusão}

O sistema de cultivo mínimo promoveu maior diâmetro e comprimento das hastes de gladíolo em ambos os cultivares quando cultivados para colheita no Dia das Mães.

Para colheita no Dia dos Namorados, o sistema de cultivo mínimo favoreceu a produção de maior número de floretes e a produção de massa seca do cultivar Red Beauty.

É possível a produção de hastes florais de gladíolo com qualidade comercial em sistema de cultivo mínimo do solo na Região do Alto Vale do Itajaí, SC.

\section{Agradecimentos}

Os autores agradecem ao Instituto Federal Catarinense (IFC) pelo apoio financeiro; e à Equipe PhenoGlad.

\section{Referências}

BERTOL, I.; COGO, N.P.; SCHICK, J.; GUDAGNIN, J.C.; AMARAL., A.J. Aspectos financeiros relacionados às perdas de nutrientes por erosão hídrica em diferentes sistemas de manejo do solo. Revista Brasileira de Ciência do Solo, Viçosa, v.31, n.1, p.133142, 2007. DOI: https://dx.doi.org/10.1590/ s0100-06832007000100014

CANTERI, M.G.; ALTHAUS, R.A.; FILHO, J.S. das V.; GIGLIOTI, E.A.; GODOY, C.V. SASM Agri: Sistema para análise e separação de médias em experimentos agrícolas pelos métodos Scoft - Knott, Tukey e Duncan. Revista Brasileira de Agrocomputação, Ponta Grossa, v.1, n.2, p.18-24, 2001.

COELHO, M.E.H.; FREITAS, F.C.J.; CUNHA, J.L.X.L.; SILVA, K.S.; GRANGEIRO, L.C.; OLIVEIRA, J.B. Coberturas do solo sobre a amplitude térmica e a produtividade de pimentão. Planta Daninha, Viçosa, v.31, n.2, p.369378, 2013. DOI: https://doi.org/10.1590/ S0100-83582013000200014

FARIAS, A.P. de; ALBUQUERQUE, A.W. de; MOURA FILHO, G.; REIS, L.S. Produtividade da Heliconia psittacorum $\times$ Heliconia pathocircinada cv. Golden Tortch sob diferentes fontes de adubação orgânica. Revista Brasileira de Engenharia Agrícola e Ambiental, Campina Grande, v.17, n.7, p.713-720, 2013. DOI: $\quad$ https://dx.doi.org/10.1590/S141543662013000700004

JUNQUEIRA, A.H.; PEETZ, M.S. O setor produtivo de flores e plantas ornamentais do Brasil no período de 2008 a 2013: atualizações, balanços e perspectivas. Revista Brasileira de Horticultura Ornamental, São Paulo, v.20, n.2, p.115-120, 2014. DOI: https:// dx.doi.10.14295/rbho.v20i2.727

PEREIRA, J.R.D.; CARVALHO, J. de A.; PAIVA, P.D.de O.; SILVA, D.J. da; SOUZA, A.M.G. de; SOUZA, K.J. de. Produção e crescimento de hastes florais de gladíolo cultivado sob diferentes tensões de água no solo. Ciência e Agrotecnologia, Lavras, v.33, n.4, p.956970, 2009. DOI: https://dx.doi.org/10.1590/ S1413-70542009000400004

ROSA, Y.B.C.J.; WOLLENBERG, S.; SILVA, E.F. da; ROSA JÚNIOR, E.G.; NUNES, M.F.; SORGATO, J.C.; ROSA, D.B.C.J.; SOARES, J.S.; ROSA, C.S.L. Desenvolvimento de gladíolo em função da adubação nitrogenada e diâmetro do cormo. Revista Brasileira de Horticultura Ornamental, São Paulo, v.20, n.1, p.87-92, 2014. DOI: https://dx.doi.10.14295/rbho. v20i1.521

SCHWAB, N. T.; UHLMANN, L. O.; BECKER, C. C.; TOMIOZZO, R.; STRECK, N. A.; BOSCO, L. C.; BONATTO, M. I.; STANCK, L. T. Gladíolo: fenologia e manejo para produção de hastes e bulbos. 1. ed. Santa Maria, 2019. 136p.

SCHWAB, N.T.; STRECK, N.A.; BECKER, C.C.; LANGNER, J.A.; UHLMANN, L.O.; BECKER, C.C..; RIBEIRO, B.S.M.R.; LANGNER, J.A.; TOMIOZZO, R. Duration of cycle and injuries due to heat and chilling in gladiolus as a function of planting dates. Ornamental Horticulture, São Paulo, v.24, n.2, p.163-173208, 2018. DOI: http://dx.doi.org/10.14295/ oh.v24i2.1174

SCHWAB, N.T.; STRECK, N.A.; BECKER, C.C.; LANGNER, J.A.; UHLMANN, L.O.; RIBEIRO, B.S.M.R. A phenological scale for the development of Gladiolus. Annals of Applied Biology, New York, v.166, v.3, p.496-507, 2015. DOI: https://doi.org/10.1111/aab.12198

SEVERINO, C.A. de M. Cultivo comercial de palma de Santa Rita (Gladiolus sp Tourm.). Brasília: Ibict, Serviço Brasileiro de Respostas Técnicas. Salvador: Rede de tecnologia da Bahia, 2007, 22 p.

SILVA, E.N.S. da; MONTANARI, R.; PANOSO, A.R.; CORREA, A.R.; TOMAZ, P.K.; FERRAUDO, A.S. Variabilidade de atributos físicos e químicos do solo e produção de feijoeiro cultivado em sistema de cultivo mínimo com irrigação. Revista Brasileira de Ciência do Solo, Viçosa, v.39, n.2, p.598-607, 2015. DOI: doi.org/10.1590/01000683rbcs20140429

TOMBOLATO, A.F.C.; UZZO, R.P.; JUNQUEIRA, A.H.; PEETZ, M. da S.; STANCATO, G.C.; ALEXANDRE, M.A.V. Bulbosas ornamentais no Brasil. Ornamental Horticulture, São Paulo, v.16, n.2, p.127-138, 2010. DOI: https://doi. org/10.14295/rbho.v16i2.553

UHLMANN, L.O.; BECKER, C.C.; TOMIOZZO, R.; STRECK, N.A.; SCHONS, A.; BALEST, D.S.; BRAGA, M. dos S.; SCHWAB, N.T.; LANGNER, J.A. Gladiolus as an alternative for diversification and profit in small rural property. Ornamental Horticulture, São Paulo, v.25, n.2, p.200-208, 2019. DOI: http://dx.doi. org/10.14295/oh.v25i2.1541

UHLMANN, L.O.; STRECK, N.A.; BECKER, C.C.; SCHAWAB, N.T.; BENENDETTI, R.P.; CHARÃO, A.S.; RIBEIRO, B.S.M.R.; SIVEIRA, W.B.; BACKERS, F.A.A.L.; ALBERTO, C.M.; MUTTONI, M.; PAULA, G.M.; TOMIOZZO, R.; BOSCO, L.C.; BECKER, D. PhenoGlad: A model for simulating development in Gladiolus. European Journal of Agronomy, v.82, part. A, p.3349, 2017. DOI: http://doi.org/10.1016/j. eja.2016.10.001 